\title{
Reliability in arthroscopic grading of cartilage lesions: results of a prospective blinded study for evaluation of inter-observer reliability
}

\author{
Gunter Spahn • Hans Michael Klinger • \\ Mike Baums • Ulrich Pinkepank • \\ Gunther O. Hofmann
}

Received: 26 February 2010/Published online: 20 January 2011

(C) Springer-Verlag 2011

\begin{abstract}
Introduction and aim Arthroscopy is a well-established method for grading cartilage lesions. This study was undertaken to evaluate the inter-observer variance of grading cartilage lesions in a real life operation.

Materials and methods Four experienced arthroscopic surgeons used diagnostic arthroscopy, one after the other, to grade cartilage lesions in a total of 16 patients who had undergone knee arthroscopy.

Results In summary, a total of 14 cartilage areas in 16 patients were graded $(n=224)$. The Cohens (Fleiss) Kappa Index for multiple investigators was $\kappa=0.052$ in the medial, $\kappa=0.300$ in the central, and $\kappa=0.107$ in the lateral surface of the patella. The indices were $\kappa=0.292$ in the medial, $\kappa=0.0 .255$ in the central, and $\kappa=0.234$ in the lateral surface of the trochlea. The inter-observer variance was $\kappa=0.193$ in the MFC mean bearing zone, $\kappa=0.116$ in the margin of the MFC, $\kappa=0.168$ in the mean bearing zone of the TM, and $\kappa=0.164$ in the TM margin. In the lateral compartment, the $\kappa$-Index was 0.309 in the LFC mean bearing zone, 0.111 in the margin of the LFC, 0.020 in the mean bearing zone of the TL, and 0.085 in the TL margin.
\end{abstract}

G. Spahn $(\square) \cdot$ U. Pinkepank

Center of Trauma and Orthopaedic Surgery Eisenach,

Sophienstr. 16, 99817 Eisenach, Germany

e-mail: spahn@pk-eisenach.de

H. M. Klinger · M. Baums

Department of Orthopaedic Surgery,

University of Göttingen, Göttingen, Germany

G. O. Hofmann

Departments of Traumatology and Orthopaedic Surgery,

University of Jena and Trauma Center Halle,

Göttingen, Germany
Conclusions The inter-observer reliability of the arthroscopic grading of cartilage lesions is poor. The major problem is the relatively large variability in differentiating between intact cartilage and lesions that consist of the softening of the cartilage and the differentiation between superficial and deep cartilage lesions. In the future, objective measurements should be developed to solve this problem.

Keywords Arthroscopy $\cdot$ Cartilage $\cdot$ Diagnostic criteria
Abbreviations
KL-grade Radiological grade of osteoarthritis according to Kellgren-Lawrence [13]
MFC Medial femoral condyle
TM Medial tibia plateau
LFC Lateral femoral condyle
TL Lateral tibia plateau
$\mathrm{Mbz} \quad$ Mean bearing zone

\section{Introduction}

Cartilage lesions are most common findings during knee arthroscopies $[1,7,10]$.

An exact grading of chondral lesions is needed for the surgeons decision to choose the treatment modalities.

Oakley and Lassere [15] reviewed the performance of cartilage grading systematically. They reviewed a total of 52 scoring systems and concluded that composite scoring systems have the best validity. Composite systems indicate a tree-dimensional description of the lesions (i.e., the affected area is calculated and the lesion's depth within the cartilage layer is described). 
The main disadvantage of all these grading systems is the individual dependence on the surgeons' subjective assessment. This may be a reason for the existence of a large number of classifications [15]. Currently, the International Cartilage Repair Society (ICRS) score often is used to describe cartilage lesions [5]. This score distinguishes four grades of the cartilage lesions: grade 0 (normal or normal), grade 1 lesions (superficial softening and/ or superficial fissures and cracks, grade 2 lesions (lesions extending down to $<50 \%$ of cartilage depth), grade 3 lesions (severely abnormal with an extension of the lesions to the subchondral bone) and finally the complete defect (severely abnormal).

In a survey among highly experienced arthroscopic surgeons, it was found that roughly half of them felt that cartilage diagnosis needs an improvement [17]. In all, there is relatively little information about the reliability of cartilage grading systems, and there are only a small number of studies about the validity of arthroscopic cartilage grading.

Former investigations have evaluated the inter-observer validity regarding arthroscopic cartilage grading. However, only videotapes were recorded by many of these investigators (Table 1).

Because arthroscopy is considered the gold standard for the grading of cartilage lesions, it was hypothesized that there would be high inter-observer agreement when this procedure was performed by experienced arthroscopic surgeons.

The aim of this blinded study is to assess the blinded cartilage scoring of experienced surgeons during a real arthroscopic operation. It shall test the inter-observer variation in ICRS grading of cartilage lesions during a real operation.

\section{Materials and methods}

\section{Patients}

Sixteen patients ( 9 male and 7 female) who were suffering from knee pain underwent arthroscopic evaluation and operation. The patients were $45.3 \pm 14.9$ (range 22-68) years old). The mean history of complaints was $6.9 \pm 4.5$ (range 3-18) months. No patient had undergone prior surgery or had suffered from an injury.

Subsequent to the approval of the regional Ethics Committee (2554-05/09), patients gave their informed consent for study-participation.

Arthroscopic operation and study protocol

The operation was performed under general anaesthesia. The leg was placed into a leg holder, and a tourniquet (300 $\mathrm{mmHg}$ ) was used. The constant irrigation pressure of Ringer Solution for arthroscopy $(80 \mathrm{mmHg})$ was assured by a pump (10 K FLUID SYSTEM, ConMed Linvatec, Utica, NY, USA). The operation was performed with a high-resolution arthroscopy system 1188HD (Stryker, Jan Jose, CA, USA).

Four highly experienced surgeons performed the operation. For all arthroscopies, antero-medial (instrumentation) and antero-lateral (arthroscope) approaches were used.

Table 1 Studies about the inter-observer reliability in arthroscopic evaluation of cartilage lesions

\begin{tabular}{|c|c|c|c|c|c|c|}
\hline Reference & $\begin{array}{l}\text { Number } \\
\text { of observer }\end{array}$ & $\begin{array}{l}\text { Number } \\
\text { of patients }\end{array}$ & Method & $\begin{array}{l}\text { Cartilage } \\
\text { grading system }\end{array}$ & Reliability & Comments \\
\hline Jerosch et al. [12] & 39 & 8 & Videotapes & No definition & $\kappa=0.663$ & \\
\hline Ayral et al. [2] & 5 & 9 & Videotapes & SFA [8] & $\kappa=0.490$ & $\begin{array}{l}\text { Improvement after 2-month } \\
\text { training to } \kappa=0.980\end{array}$ \\
\hline Brismar et al. [4] & 4 & 19 & Videotapes & $\begin{array}{l}\text { Outerbridge [16] } \\
\text { SFA [8] }\end{array}$ & $\kappa=0.650$ & $\begin{array}{l}\text { No differences between the } \\
\text { score } \\
\text { Systematic failure of } \\
\text { different surgeons }\end{array}$ \\
\hline Javed et al. [11] & 3 & 78 & $\begin{array}{l}\text { Life operation } \\
\text { No description of } \\
\text { evaluated cartilage } \\
\text { areas }\end{array}$ & Outerbridge [16] & $\begin{array}{l}\text { Inter-observer } \\
\text { variation } 20 \%\end{array}$ & \\
\hline Cameron et al. [6] & 9 & 6 & $\begin{array}{l}\text { Videotapes, human } \\
\text { cadaver }\end{array}$ & Outerbridge [16] & $\kappa=0.800$ & $\begin{array}{l}\text { Reliability depends on } \\
\text { evaluated region: best } \\
\text { patella }(\kappa=0.800) \text {, worst } \\
\text { lateral tibia }(\kappa=0.560)\end{array}$ \\
\hline Marx et al. [14] & 3 & 31 & Videotapes & Outerbridge [16] & $\begin{array}{l}\text { Inter-observer } \\
\text { variation } 17 \%\end{array}$ & \\
\hline
\end{tabular}


All surgeons had to grade the cartilage lesions in welldefined knee areas (Fig. 1). After evaluation, every investigator anonymously documented the results of the cartilage grading. These results were sampled in an SPSS database by an independent expert. During the evaluation, the surgeons had no knowledge about the results of the other investigators.

After the cartilage grading, surgeon I performed the operation in dependence of intraarticular pathologies: medial meniscectomy $(n=13)$, microfracturing $(n=2)$ and bipolar thermochondroplasty of deep cartilage lesions $(n=3)$, suture of the medial meniscus $(n=1)$, and patella realignment $(n=1)$.

Evaluation and grading

All cartilage lesions were classified according to the ICRS guidelines [5].

\section{Statistics}

SPSS software (version 13.0, SPSS Inc, Chicago, IL, USA) was used for all statistical evaluations.

The multirater Kappa (Fleiss) index was used to measure the "inter-rater-agreement" between the surgeons [3].

The Kolmogorov-Smirnov test was used to assess the normality of distributions. Analysis of variance (ANOVA), along with the Newman-Keuls test, was used for mean comparisons. The Chi-squared test was used for comparison of frequencies. Correlations are expressed by the Pearson Index $(R)$. A $p$ value $<0.05$ was considered significant.

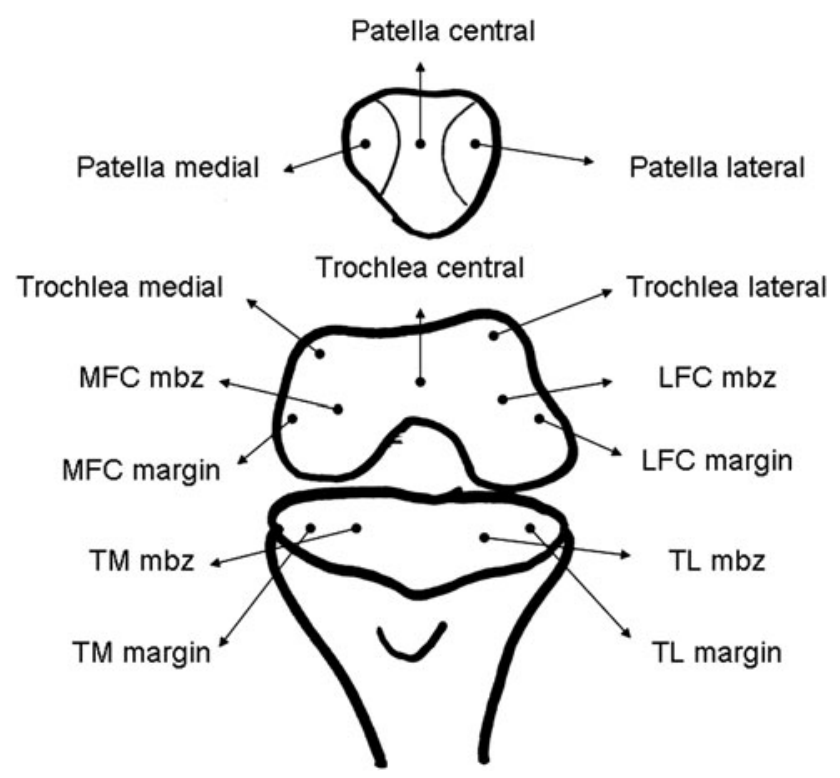

Fig. 1 Regions of interest for the grading of cartilage lesions. $M F C$ medial femoral condyle, $T M$ medial tibia plateau, $L F C$ lateral femoral condyle, $T L$ lateral tibia plateau, $m b z$ mean bearing zone

\section{Results}

Grading of cartilage lesions and inter-observer variance

In summary, a total of 14 cartilage areas in 16 patients were graded $(n=224)$. In 39 cases $(17.4 \%)$, there was complete agreement between the four investigators, in 84 cases (37.5\%) between three investigators, and in 101 cases (45.1\%) between two investigators (Table 2).

In 39 cases $(17.4 \%)$, the investigators graded the cartilage lesions with an interval of 2 degrees and in 41 cases $(18.3 \%)$ with an interval of 3 degrees of the ICRS classification. In the rest of regions $(n=105,46.9 \%)$, the results of grading included one-step differences (Table 3).

The Cohens (Fleiss) Kappa Index for multiple investigators was $\kappa=0.052$ in the medial, $\kappa=0.300$ in the central, and $\kappa=0.107$ in the lateral surface of the patella. The indices were $\kappa=0.292$ in the medial, $\kappa=0.0 .255$ in the central, and $\kappa=0.234$ in the lateral surface of the trochlea.

The inter-observer variance was $\kappa=0.193$ in the MFC mean bearing zone, $\kappa=0.116$ in the margin of the MFC, $\kappa=0.168$ in the mean bearing zone of the TM, and $\kappa=0.164$ in the TM margin. In the lateral compartment, the $\kappa$-Index was 0.309 in the LFC mean bearing zone, 0.111 in the margin of the LFC, 0.020 in the mean bearing zone of the TL, and 0.085 in the TL margin.

Table 2 Inter-observer variation in evaluation of cartilage lesions

\begin{tabular}{lllc}
\hline Region & $\begin{array}{l}\text { Complete } \\
\text { agreement } \\
\text { between the } 4 \\
\text { investigators }\end{array}$ & $\begin{array}{l}\text { Agreement } \\
\text { between 3 } \\
\text { investigators }\end{array}$ & $\begin{array}{l}\text { Agreement } \\
\text { between 2 } \\
\text { investigators }\end{array}$ \\
\hline Patella medial & & 5 & 11 \\
Patella central & 4 & 4 & 8 \\
Patella lateral & 2 & 4 & 10 \\
Trochlea medial & 4 & 4 & 8 \\
Trochlea central & 3 & 6 & 7 \\
Trochlea lateral & 3 & 8 & 5 \\
MFC (mbc) & 1 & 7 & 8 \\
MFC (margin) & 1 & 10 & 5 \\
TM (mbz) & 2 & 6 & 8 \\
TM (margin) & 1 & 8 & 7 \\
LCF (mbz) & 7 & 7 & 2 \\
LFC (margin) & 8 & 6 & 2 \\
TL (mbz) & & 6 & 10 \\
Tl (margin) & 3 & 3 & 10 \\
\hline
\end{tabular}

$M F C$ medial femoral condyle, $T M$ medial tibia plateau, $L F C$ lateral femoral condyle, $T L$ lateral tibia plateau, $m b z$ mean bearing zone 
Table 3 Interval of (degrees of the ICRS classification) in evaluation of cartilage lesions

\begin{tabular}{llcll}
\hline Region & $\begin{array}{l}\text { Complete } \\
\text { agreement } \\
\text { between the } \\
4 \text { investigators }\end{array}$ & $\begin{array}{l}1 \text { grade } \\
\text { interval }\end{array}$ & $\begin{array}{l}2 \text { grade } \\
\text { interval }\end{array}$ & $\begin{array}{l}3 \text { grade } \\
\text { interval }\end{array}$ \\
\hline Patella medial & & 8 & 4 & 4 \\
Patella central & 4 & 6 & 6 & \\
Patella lateral & 2 & 5 & 8 & 1 \\
Trochlea medial & 4 & 8 & 1 & 3 \\
Trochlea central & 3 & 6 & 6 & 1 \\
Trochlea lateral & 3 & 9 & 3 & 1 \\
MFC (mbc) & 1 & 9 & 1 & 5 \\
MFC (margin) & 1 & 10 & 2 & 3 \\
TM (mbz) & 2 & 8 & 4 & 2 \\
TM (margin) & 1 & 10 & 3 & 2 \\
LCF (mbz) & 7 & 7 & & 2 \\
LFC (margin) & 8 & 8 & & \\
TL (mbz) & & 7 & & 9 \\
Tl (margin) & 3 & 4 & 1 & 8
\end{tabular}

MFC medial femoral condyle, $T M$ medial tibia plateau, $L F C$ lateral femoral condyle, $T L$ lateral tibia plateau, $m b z$ mean bearing zone

\section{Discussion}

The hypothesis of our study was that because arthroscopy is the gold standard for the grading of cartilage lesions, there would be high inter-observer agreement when this procedure was performed by experienced arthroscopic surgeons. This hypothesis was not supported by the results of our study.

Four surgeons examined a total of 224 cartilage regions from 16 knees. In each knee, 14 well-defined regions were chosen. The Kappa index ranged from 0.052 to 0.308 , and less than $20 \%$ of the surgeons were in complete agreement. This suggests very poor reliability in the arthroscopic grading of cartilage lesions.

Cartilage lesions are frequent findings during knee arthroscopic knee procedures. The grading of these lesions often influences the surgeon's decision about therapeutic approaches. Therefore, a precise standardized grading system for these lesions is needed.

Different scoring methods have been used in the classification of cartilage lesions [15]. In general, these scoring systems differentiate lesions into three or four grades: superficial lesions (softening, superficial fissures), middle grade lesions that do not extend into the subchondral bone, deep cartilage lesions that involve alterations of the subchondral bone and complete defects with exposed subchondral bone. In contrast, the French Society of Arthroscopy (SFA) method describes the severity of cartilage lesions using a visual analogue scale that ranges from
0 (intact cartilage) to 100 (complete defect) [8]. Using this system, the surgeon always determines the depth of the cartilage lesions in relation to the subchondral bone. This subjective determination is the major problem with this method.

The arthroscopic method of cartilage lesion grading has the advantage of direct visualization and the added benefit of possible palpation with a hooked probe.

With the arthroscopic method, the region in which the lesions are located can be precisely recorded (e.g., the mean bearing zone of the medial femoral condyle). Additionally, a calculation (using the graduations of the hook) or an exact measurement (a PC-based measurement) of the dimensions of the lesion can be easily performed. As previously mentioned, the most important step in the grading of cartilage lesions depends on the surgeon's subjective estimation. The cartilage is described by the characteristics of the lesions: intact, nearly intact, superficial softening or fissures, deep lesions extending to the subchondral bone or a complete defect with exposed subchondral bone.

Therefore, the arthroscopic grading of cartilage lesions is fraught with pitfalls and variable results are obtained due to the subjective estimations of surgeons, differences in the manual force applied during probing, the designs of different hooked probes as well as other factors.

These pitfalls are reflected in a recently performed survey of surgeons. More than 50\% of well-trained arthroscopic surgeons stated that the arthroscopic grading of cartilage lesions "needs urgently an improvement" [17].

The majority of the other investigations (Table 1) into the quality of arthroscopic cartilage grading (Table 1), retrospectively re-evaluated cartilage lesions from videotaped procedures.

The only investigation in the literature [11] that was performed during a live operation did not use clear definitions for cartilage grading.

In our investigation, the cartilage lesions were graded during live operations that were performed by four different surgeons. The regions of interest were clearly defined, and we used the well-defined cartilage (ICRS) scoring system.

In contrast to the previous studies, we compared the precise grades of cartilage lesions in 14 regions of the knee joint. These differences may explain why we observed very low inter-observer agreement. Most of the differences in scoring occurred in the differentiation of intact cartilage from lesions that consisted of softening and fissures and in the differentiation of grade II and grade III lesions.

This study has some limitations. The number of patients involved was relatively small. This was caused by the evaluation of live operations and the large number of regions examined in each knee (visually and by hook palpation). Furthermore, no calculations of the extensions 
of the lesions were performed. The regions studied were clearly defined, which allowed for an overview of the cartilage status of the knee. In addition, the calculation of the lesion diameters was simple (it involved only the graduations of the hook or software-based measurements). Despite these limitations, we have studied the main problem - the evaluation of the depth of the lesions relative to the subchondral bone.

Improvements to the conventional methods of arthroscopic cartilage lesion grading could involve the better training of arthroscopic surgeons, external quality management or improvements in the scoring systems. However, these strategies would not avoid the major problem in arthroscopic cartilage grading: the individual subjective error introduced by a surgeon's estimation.

Objective arthroscopic measurements have been described in the previous reports. The arthroscopic measurement of chondral stiffness is possible [9, 19]; however, it is more practical to measure cartilage degeneration using spectroscopic procedures (e.g., near infrared light) [18]. These objective methods have only recently been developed. The refinement of existing scoring systems or the creation of new ones would not solve the major problem of the grading of cartilage lesions: the high subjective nature of a surgeon's clinical evaluations.

\section{Conclusion}

The inter-observer reliability of the arthroscopic grading of cartilage lesions is poor. The major problem is the relatively large variability in differentiating between intact cartilage and lesions that consist of the softening of the cartilage and the differentiation between superficial and deep cartilage lesions. In the future, objective measurements should be developed to solve this problem.

\section{References}

1. Aroen A, Loken S, Heir S, Alvik E, Ekeland A, Granlund OG, Engebretsen L (2004) Articular cartilage lesions in 993 consecutive knee arthroscopies. Am J Sports Med 32:211-215

2. Ayral X, Gueguen A, Ike RW, Bonvarlet JP, Frizziero L, Kalunian K, Moreland LW, Myers S, O'Rourke KS, Roos H, Altman R, Dougados M (1998) Inter-observer reliability of the arthroscopic quantification of chondropathy of the knee. Osteoarthritis Cartilage 6:160-166

3. Bortz J, Lienert GA (2008) Statistics for clinical investigation. Springer, Heidelberg

4. Brismar BH, Wredmark T, Movin T, Leandersson J, Svensson O (2002) Observer reliability in the arthroscopic classification of osteoarthritis of the knee. J Bone Joint Surg Br 84:42-47

5. Brittberg M, Winalski CS (2003) Evaluation of cartilage injuries and repair. J Bone Joint Surg Am 85-A(2):58-69

6. Cameron ML, Briggs KK, Steadman JR (2003) Reproducibility and reliability of the outerbridge classification for grading chondral lesions of the knee arthroscopically. Am J Sports Med 31:83-86

7. Curl WW, Krome J, Gordon ES, Rushing J, Smith BP, Poehling GG (1997) Cartilage injuries: a review of 31, 516 knee arthroscopies. Arthroscopy 13:456-460

8. Dougados M, Ayral X, Listrat V, Gueguen A, Bahuaud J, Beaufils P, Beguin JA, Bonvarlet JP, Boyer T, Coudane H (1994) The SFA system for assessing articular cartilage lesions at arthroscopy of the knee. Arthroscopy 10:69-77

9. Duda GN, Kleemann RU, Bluecher U, Weiler A (2004) A new device to detect early cartilage degeneration. Am J Sports Med 32:693-698

10. Hjelle K, Solheim E, Strand T, Muri R, Brittberg M (2002) Articular cartilage defects in 1,000 knee arthroscopies. Arthroscopy 18:730-734

11. Javed A, Siddique M, Vaghela M, Hui AC (2002) Interobserver variations in intra-articular evaluation during arthroscopy of the knee. J Bone Joint Surg Br 84:48-49

12. Jerosch J, Castro WH, de Waal Malefijt MC, Busch M, van Kampen A (1997) Interobserver variation in diagnostic arthroscopy of the knee joint. "How really objective are arthroscopic findings?”. Unfallchirurg 100:782-786

13. Kellgren JH, Lawrence JS (1957) Radiological assessment of osteo-arthrosis. Ann Rheum Dis 16:494-502

14. Marx RG, Connor J, Lyman S, Amendola A, Andrish JT, Kaeding C, McCarty EC, Parker RD, Wright RW, Spindler KP (2005) Multirater agreement of arthroscopic grading of knee articular cartilage. Am J Sports Med 33:1654-1657

15. Oakley SP, Lassere MN (2003) A critical appraisal of quantitative arthroscopy as an outcome measure in osteoarthritis of the knee. Semin Arthritis Rheum 33:83-105

16. Outerbridge RE (1957) The etiology of chondromalacia patellae. J Bone Joint Surg Br 43:752-757

17. Spahn G, Klinger HM, Hofmann GO (2009) How valid is the arthroscopic diagnosis of cartilage lesions? Results of an opinion survey among highly experienced arthroscopic surgeons. Arch Orthop Trauma Surg 129:1117-1121

18. Spahn G, Plettenberg H, Kahl E, Klinger HM, Muckley T, Hofmann GO (2007) Near-infrared (NIR) spectroscopy. A new method for arthroscopic evaluation of low grade degenerated cartilage lesions. Results of a pilot study. BMC Musculoskelet Disord 8:47

19. Uchio Y, Ochi M, Adachi N, Kawasaki K, Iwasa J (2002) Arthroscopic assessment of human cartilage stiffness of the femoral condyles and the patella with a new tactile sensor. Med Eng Phys 24:431-435 